\title{
Effects of $\boldsymbol{\kappa}$-Carrageenan on the Non-Specific Defense System of Carp Cyprinus carpio
}

\author{
Kazuhiro Fujiki, Dong-Ho Shin, Miki Nakao, \\ and Tomoki Yano ${ }^{\dagger}$ \\ Laboratory of Marine Biochemistry, Faculty of Agriculture, Kyushu University, \\ Fukuoka 812-81, Japan \\ (Received April 28, 1997)
}

\begin{abstract}
Carp which have received an intraperitoneal injection of $\kappa$-carrageenan show a high survival rate after being challenged with pathogenic bacteria. In order to elucidate the mechanism underlying the immunoenhancement, we investigated its effects on the non-specific defense system of carp. $\kappa$-Carrageenan had little influence on the activity of the alternative complement pathway or on the phagocytic and respiratory burst activities of head kidney phagocytes (HKP), yet it greatly elevated the migration of HKP to the peritoneal cavity. Since the migrated HKP (especially macrophages) showed a high phagocytic activity, it is highly probable that the early elimination of challenge bacteria by such mobilized and activated phagocytes was responsible for the high survival rate of the $\kappa$-carrageenan-injected fish. It was also found that the phagocytic activity of the migrated head kidney macrophages was elevated not by resident peritoneal cells, but by leukocytes which had migrated to the peritoneal cavity. This indicates that the migrated leukocytes produced and secreted a factor(s) with macrophage activation potency.
\end{abstract}

Key words: $\kappa$-carrageenan, Chondrus ocellatus, carp, Cyprinus carpio, non-specific defense system, phagocytosis, respiratory burst activity, peritoneal exudate cells

It has been shown that antitumor polysaccharides (lentinan, schizophyllan, scleroglucan) derived from fungi (Lentinus edodes, Schizophyllum commune, Sclerotium glucanicum) enhance the resistance of carp against Edwardsiella tarda and Aeromonas hydrophila infections and the resistance of yellowtail against Lactococcas garvieae (syn. Enterococcus seriolicida) infection. ${ }^{1-3)}$ A similar observation was made by Robertsen et al. ${ }^{4)}$ who reported that a polysaccharide (M-glucan) obtained from yeast Saccharomyces cerevisiae enhanced resistance against Yersinia ruckeri, Vibrio anguillarum and Vibrio salmonicida in the Atlantic salmon Salmo salar.

It is known that some red algae contain antitumor polysaccharides. For example, $\kappa$-carrageenan, which was isolated from Eucheuma spinosum, and $\lambda$-carrageenan, which was isolated from Irish moss Chondrus crispus, inhibited the growth of Ehrlich carcinoma in mice. ${ }^{5}$ Porphyran, which was isolated from Porphyra yezoensis, was also shown to have antitumor activity. ${ }^{5}$ Recently, it was found that injections of $\kappa$-carrageenan isolated from tsunomata Chondrus ocellatus also enhance the resistance of carp against $E$. tarda and $A$. hydrophila infections. ${ }^{6}$ The molecular structure of carrageenans, which are linear sulfated poly-D-galactans composed of repeating disaccharide units, ${ }^{7}$ is quite different from that of fungus- and yeast-derived polysaccharides $(1,6$-branched- $\beta$ - 1,3 -glucans), which have been shown to possess the common fea- ture of activating the non-specific defense factors of fish, such as complement, ${ }^{1,2,8)}$ lysozyme ${ }^{8)}$ and phagocytic cells. ${ }^{1,9-11)}$ This study was undertaken to examine whether fish injected with $\kappa$-carrageenan were immunoenhanced through similar or the same mechanisms as fish injected with fungus-derived polysaccharides.

\section{Materials and Methods}

\section{Reagents}

Glycoletherdiaminetetraacetic acid (EGTA) was purchased from Wako Pure Chemical Industries, Ltd., Osaka. RPMI-1640 and Hanks' balanced salt solution (HBSS) were obtained from Nissui Pharmaceutical Co., Ltd., Tokyo. Penicillin-streptomycin mixture and fetal bovine serum (FBS) were the products of Bio Whittaker Inc., Walkersville, MD. Percoll was obtained from Pharmacia Biotech, Uppsala, Sweden. Bakers' yeast was purchased from Oriental Yeast Co., Ltd., Tokyo. Nitroblue tetrazolium (NBT) and dimethyl sulfoxide (DMSO) were obtained from Sigma Chemical Co., St. Louis, MO. Lentinan and $\kappa$-carrageenan were isolated in our laboratory from shiitake Lentinus edodes ${ }^{12)}$ and tsunomata Chondrus ocellatus, ${ }^{6)}$ respectively.

\section{Fish}

Carp (45-54 g) were purchased from a fish farm in

\footnotetext{
${ }^{\dagger}$ Correspondence: Laboratory of Marine Biochemistry, Faculty of Agriculture, Kyushu University, Hakozaki, Higashi-ku, Fukuoka 812-81, Japan.
} 
Fukuoka Prefecture and acclimated for about 3 weeks at $22^{\circ} \mathrm{C}$ in $60 \mathrm{l}$ aquaria filled with recirculating well water. During acclimation and experiments, fish were fed with commercial dry pellets (Nippon Formula Feed Mfg. Co., Ltd., Yokohama).

\section{Serum}

Blood was taken from the dorsal aorta of carp using a syringe and allowed to clot at $20^{\circ} \mathrm{C}$ for $30 \mathrm{~min}$ and cooled at $0^{\circ} \mathrm{C}$ for $1 \mathrm{~h}$. After centrifugation, the serum was separated and stored at $-80^{\circ} \mathrm{C}$ until use.

\section{Assay of Alternative Complement Pathway (ACP) Activi-} ty

Serum ACP activity was assayed according to Yano et al. ${ }^{13)}$ Briefly, individual $0.5 \mathrm{ml}$ aliquots of serially diluted carp serum were mixed with $0.2 \mathrm{ml}$ of rabbit erythrocyte suspension $\left(2 \times 10^{8}\right.$ cells $\left./ \mathrm{m} l\right)$ and the mixture was incubated at $20^{\circ} \mathrm{C}$ at $\mathrm{pH} 7.0$ for $2 \mathrm{~h}$ in the presence of $10 \mathrm{~mm}$ of EGTA and $10 \mathrm{mM}$ of $\mathrm{MgCl}_{2}$. The hemolytic reaction was stopped by adding $1.4 \mathrm{~m} /$ of gelatin-veronal buffer containing $10 \mathrm{~mm}$ EDTA. After centrifugation, absorbance of the supernatant was measured at $414 \mathrm{~nm}$, and ACP activity (ACH50) was calculated from the degree of hemolysis.

\section{Culture Media}

Culture media used in this experiment and their abbreviations are as follows. RPMI-1640-P: RPMI-1640 buffered with $10 \mathrm{mM} \mathrm{Na} / \mathrm{K}$-phosphate (pH 7.4); RPMI-1640-PA: RPMI-1640-P supplemented with antibiotics $(100 \mathrm{IU} / \mathrm{m} l$ of penicillin and $100 \mu \mathrm{g} / \mathrm{ml}$ of streptomycin); RPMI-1640PAC: RPMI-1640-P supplemented with antibiotics and $0.31 \%$ trisodium citrate; HBSS-P: HBSS buffered with 5 $\mathrm{mM} \mathrm{Na} / \mathrm{K}$-phosphate (pH 7.4).

\section{Preparation of the Phagocytes in the Peripheral Blood, Head Kidney and Peritoneal Cavity}

After anaesthetizing the fish with $30 \mathrm{ppm} 2$-methylquinoline, phagocytes were separated from the peripheral blood, head kidney and peritoneal cavity as follows: 1) The peripheral blood was taken from the dorsal aorta using a heparinized syringe. After centrifugation at $500 \times \mathrm{g}$ for $3 \mathrm{~min}$, the leukocytes on the red blood cell layer were separated and suspended in $5 \mathrm{~m} l$ of ice-cold RPMI-1640PAC. 2) The head kidney was taken out of the fish, placed in a Petri-dish (Falcon 1007, Becton Dickinson Labware, NJ) containing $10 \mathrm{~m} l$ of ice-cold RPMI-1640-PAC, and minced by placing it between two siliconized glass slides. Then, connective tissues and cell aggregates were removed by centrifugation (head kidney cells, HKC). 3) The peritoneal cavity was rinsed five times with $1 \mathrm{~m} l$ of ice-cold RPMI-1640-PAC using a siliconized Pasteur pipette. The washings were pooled and debris was removed by centrifugation (resident peritoneal cells, RPC, or peritoneal exudate cells, PEC).

The leukocyte suspensions obtained above were separately layered over a discontinuous Percoll density gradient consisting of $2 \mathrm{ml}$ each of $33 \%$ and $69 \%$ iso-osmotic Percoll and centrifuged at $500 \times g$ for $30 \mathrm{~min}$ at $5^{\circ} \mathrm{C}$. The cells at the $33 \%-69 \%$ interface were harvested and used as peripheral blood phagocyte (PBP), head kidney phagocyte (HKP) or peritoneal exudate phagocyte (PEP) fractions.

The cellular viability of PBP, HKP and PEP in respective fractions was $>97 \%$ when examined by the trypan blue dye exclusion test. Though respective fractions contained lymphocyte, they could be distinguished from phagocytes (predominantly macrophages and neutrophils) by use of a phase-contrast microscope, and were excluded from counting. ${ }^{14)}$

\section{Assay of Phagocytic Activity}

An aliquot $(0.1 \mathrm{~m} l)$ of phagocyte suspension $\left(1 \times 10^{7}\right.$ cells $/ \mathrm{ml}$ of RPMI-1640-P) was mixed with an equal volume of RPMI-1640-P containing $10 \%$ FBS and $5 \times 10^{7}$ cells $/ \mathrm{ml}$ of heat-treated $\left(100^{\circ} \mathrm{C}, 1 \mathrm{~h}\right)$ bakers' yeast. The mixture was incubated at $25^{\circ} \mathrm{C}$ for $1 \mathrm{~h}$ with occasional shaking, and $50 \mu \mathrm{l}$ of the mixture was smeared on a glass slide, air-dried and stained with Wright's solution, and phagocytic index (PI) was determined by enumerating 500 phagocytes at random under a microscope. ${ }^{15)}$

\section{Assay of Respiratory Burst Activity}

Respiratory burst activity of phagocytes was measured by the NBT method ${ }^{16}$ ) with some modifications. Phagocytes were suspended in HBSS-P at a concentration of $1 \times 10^{7}$ cells $/ \mathrm{ml}$ and $0.1 \mathrm{ml}$ of the suspension was mixed with $0.5 \mathrm{ml}$ of HBSS-P containing $0.1 \%$ NBT and $2.5 \times 10^{7}$ cells $/ \mathrm{m} l$ of bakers' yeast. The mixture was incubated at $25^{\circ} \mathrm{C}$ for $2 \mathrm{~h}$ with occasional shaking. After centrifugation, the pellet was washed with $70 \%$ methanol, airdried and mixed with $0.5 \mathrm{~m} /$ of $2 \mathrm{M} \mathrm{KOH}$, and the mixture was sonicated for $10 \mathrm{~min}$ and then extracted with $0.5 \mathrm{~m} l$ DMSO for $10 \mathrm{~min}$. After centrifugation, absorbance of the supernatant was measured at $630 \mathrm{~nm}$ using a $1 \mathrm{~cm}$ light-path cuvette and respiratory burst activity was expressed as $\mathrm{A}_{630 \mathrm{~nm}}$ per $10^{6}$ phagocytes.

\section{Preparation of the Macrophages and Granulocytes in the Head Kidney and Peritoneal Cavity}

HKC and PEC, which were separated from the head kidney and peritoneal cavity, were suspended in $10 \mathrm{~m} l$ each of ice-cold RPMI-1640-PAC and separately layered over a discontinuous Percoll density gradient consisting of $2 \mathrm{ml}$ each of $33 \%, 51 \%$ and $69 \%$ iso-osmotic Percoll and centrifuged at $500 \times g$ for $30 \mathrm{~min}$. The cells at the $33 \%-51 \%$ interface and $51 \%-69 \%$ interface were harvested and used as head kidney macrophages (HKM, macrophages: granulocytes $=8.0: 2.0$ ) or peritoneal exudate macrophages (PEM, macrophages: granulocytes $=8.1: 1.9$ ), and head kidney granulocytes (HKG, macrophages: granulocytes $=2.3: 7.7$ ) or peritoneal exudate granulocytes (PEG, macrophages: granulocytes $=1.4: 8.6$ ), respectively.

The cellular viability of all preparations was $>97 \%$ when examined by the trypan blue dye exclusion test.

\section{Preparation of $\kappa$-Carrageenan-treated Resident Peritoneal Cells}

Resident peritoneal cells (RPC), which were separated from normal fish, were suspended in RPMI-1640-PA containing $50 \mu \mathrm{g} / \mathrm{m} l$ of $\kappa$-carrageenan and incubated at $22^{\circ} \mathrm{C}$ for $3 \mathrm{~h}$. After centrifugation, the precipitated cells were washed 5 times with RPMI-1640-PA and suspended in the same culture medium at a concentration of $1 \times 10^{6}$ 
936

cells $/ \mathrm{m} l$.

\section{Statistics}

Student's t-test was employed to evaluate the level of significance and the difference was considered significant when $P<0.05$.

\section{Results}

\section{Complement-consuming Potency of $\kappa$-Carrageenan}

$\kappa$-Carrageenan was dissolved in saline to a concentration of $0.25 \mathrm{mg} / \mathrm{ml}$, and $50 \mu l$ of the solution was mixed with $200 \mu \mathrm{l}$ of normal carp serum or saline and incubated at $20^{\circ} \mathrm{C}$ for $30 \mathrm{~min}$. After centrifugation, the residual ACP activity (ACH50) of the supernatant was measured. For reference, the same experiment was carried out on a fungus-derived polysaccharide (lentinan).

As shown in Table 1, lentinan consumed $42 \%$ of the ACP activity, while $\kappa$-carrageenan had no effect on the ACP activity, indicating that in contrast to lentinan, $\kappa$-carrageenan does not activate carp complement.

\section{Effects of $\kappa$-Carrageenan on Phagocytic and Respiratory} Burst Activities of HKP

Groups of 10 fish each were injected intraperitoneally (i.p.) with $2 \mathrm{mg} / 100 \mathrm{~g}$ body weight of $\kappa$-carrageenan or lentinan, or with saline alone and two days later, the phagocytic and respiratory burst activities of HKP were measured.

As seen in Table 1, injection of lentinan significantly elevated both phagocytic and respiratory burst activities of HKP, while $\kappa$-carrageenan had little effect.

\section{Changes in the Number of PEP after $\kappa$-Carrageenan Injec- tions}

Thirty fish were injected i.p. with $2 \mathrm{mg} / 100 \mathrm{~g}$ body weight of $\kappa$-carrageenan and two days later, boosted with the same dose. Control fish ( 30 fish) received saline alone on the same days. Five fish from each group were sacrificed every day for 6 days and the number of PEP was counted for each individual fish.

The number of PEP reached a peak $\left(9.1 \times 10^{6}\right.$ cells $/$ fish $)$ one day after the initial injection of $\kappa$-carrageenan, and

Table 1. Effects of $\kappa$-carrageenan on the activity of carp complement and head kidney phagocytes

\begin{tabular}{cccc}
\hline Polysaccharide & $\begin{array}{c}\text { Relative } \\
\text { residual } \\
\text { ACP } \\
\text { activity }\end{array}$ & $\begin{array}{c}\text { Relative } \\
\text { phagocytic } \\
\text { activity } \\
\text { of HKP }\end{array}$ & $\begin{array}{c}\text { Relative } \\
\text { respiratory } \\
\text { burst activity } \\
\text { of HKP*3 }\end{array}$ \\
\hline K-Carrageenan & 0.98 & 1.13 & 1.04 \\
Lentinan & 0.58 & 2.21 & 1.43 \\
Control & 1.00 & 1.00 & 1.00 \\
\hline
\end{tabular}

* $_{1}$ Polysaccharide was dissolved in saline to a concentration of $0.25 \mathrm{mg} / \mathrm{m} l$, and $50 \mu l$ of the solution or saline was mixed with $200 \mu l$ of normal carp serum and incubated at $20^{\circ} \mathrm{C}$ for $30 \mathrm{~min}$. After centrifugation, residual ACP activity within the supernatant was measured according to Yano et al. ${ }^{13)}$

*2 Head kidney phagocytes (HKP) were incubated with bakers' yeast at a ratio of $1: 10$ at $25^{\circ} \mathrm{C}$ for $1 \mathrm{~h}$, and phagocytic index (PI) was calculated according to Matsuyama et al. ${ }^{15)}$ Each value represents the mean of 10 fish.

${ }^{*} 3$ Measured according to Rook et al. ${ }^{16)}$ HKP were incubated with bakers' yeast at a ratio of $1: 12.5$ at $25^{\circ} \mathrm{C}$ for $2 \mathrm{~h}$ in $0.1 \% \mathrm{NBT}$ solution. Each value represents the mean of 10 fish. ujiki et al.

then gradually decreased (Fig. 1). The booster injection did not increase the number of PEP. This would be because the second injection was made just after the number of PEP had reached the maximum. In the control fish, which received saline alone, there was no increase in the number of PEP throughout the experiment.

\section{Origin of the Phagocytes which Migrated to the Peritoneal Cavity}

Groups of 5 fish each were injected with $\kappa$-carrageenan ( $2 \mathrm{mg} / 100 \mathrm{~g}$ body weight) or saline alone and $12 \mathrm{~h}$ later, the number of HKP, PBP and PEP was counted. The number of PBP was estimated from the total blood volume which was calculated from the body weight. ${ }^{17}$

As shown in Table 2 , injection of $\kappa$-carrageenan resulted in a great decrease in the number of HKP and 3.3- and 14.2-fold increases in the number of PBP and PEP, respectively. This indicates that the phagocytes, which migrated

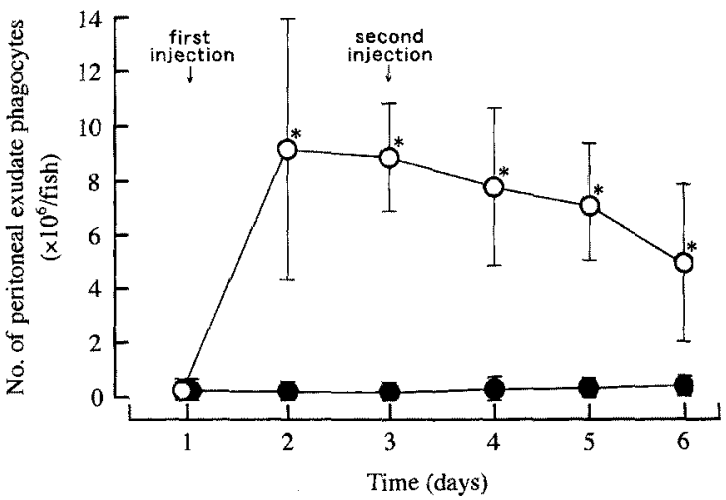

Fig. 1. Changes in the number of carp peritoneal exudate phagocytes after the $\kappa$-carrageenan injections $(2 \mathrm{mg} / 100 \mathrm{~g}$ body weight).

$0, \kappa$-carrageenan; $\bullet$, saline (control). Data represent the means \pm S.E. $(n=5)$. *Significantly different from the control.

Table 2. Changes in the number of phagocytes in the head kidney, peripheral blood and peritoneal cavity of $\kappa$-carrageenan-inject. ed fish

\begin{tabular}{|c|c|c|c|}
\hline \multirow{2}{*}{ Fish } & \multirow{2}{*}{ Organ } & \multicolumn{2}{|c|}{ No. of phagocytes $\left(\times 10^{5} \text { cells } / \text { fish }\right)^{* 1}$} \\
\hline & & Pre-injection & Post-injection \\
\hline \multirow{3}{*}{$\begin{array}{c}\kappa \text {-Carrageenan- } \\
\text { injected fish }\end{array}$} & Head kidney & $138.5 \pm 28.9$ & $80.0 \pm 24.5^{* 2}$ \\
\hline & $\begin{array}{l}\text { Peripheral } \\
\text { blood }\end{array}$ & $12.3 \pm 2.0$ & $40.2 \pm 17.2^{* 2}$ \\
\hline & $\begin{array}{l}\text { Peritoneal } \\
\text { cavity }\end{array}$ & $3.5 \pm 0.6$ & $49.8 \pm 23.9^{* 2}$ \\
\hline \multirow{3}{*}{$\begin{array}{l}\text { Saline-injected } \\
\text { fish }\end{array}$} & Head kidney & - & $127.2 \pm 20.8$ \\
\hline & $\begin{array}{l}\text { Peripheral } \\
\text { blood }\end{array}$ & - & $12.4 \pm 2.4$ \\
\hline & $\begin{array}{l}\text { Peritoneal } \\
\text { cavity }\end{array}$ & $\longrightarrow$ & $3.2 \pm 0.8$ \\
\hline
\end{tabular}

* Fish were injected i.p. with $\kappa$-carrageenan ( $2 \mathrm{mg} / 100 \mathrm{~g}$ body weight) or saline alone and $12 \mathrm{~h}$ later, the number of phagocytes in the head kidney, peripheral blood and peritoneal cavity was counted. Each value represents the mean of 5 fish.

$*_{2}$ Significantly different from the respective value of saline-injected fish. 


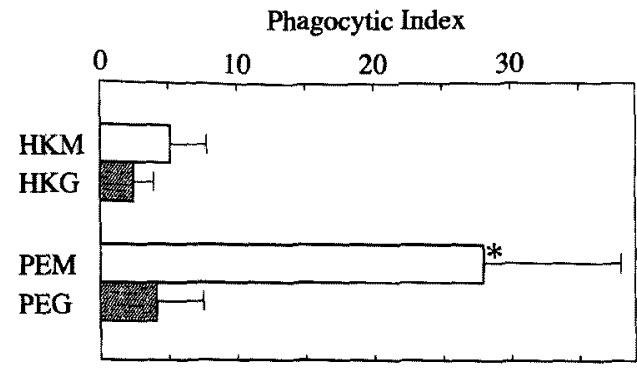

Fig. 2. Phagocytic activity of head kidney macrophages and granulocytes which were mobilized to the peritoneal cavity.

Five fish were injected intraperitoneally with $\kappa$-carrageenan and $12 \mathrm{~h}$ later the phagocytic activity of macrophages and granulocytes in the head kidney (HKM and HKG) and those in the peritoneal cavity (PEM and PEG) was assayed.

[] , macrophages; $\mathbb{N}$, granulocytes. Columns and bars represent the means \pm S.E. $(n=5)$. "Significantly different from HKM.

to the peritoneal cavity, were mostly supplied from the head kidney via the blood circulation.

\section{Phagocytic Activity of the Migrated Phagocytes}

Groups of 5 fish were injected with $\kappa$-carrageenan $(2$ $\mathrm{mg} / 100 \mathrm{~g}$ body weight) and $12 \mathrm{~h}$ later, phagocytic activity of HKM, HKG, PEM and PEG was assayed.

As seen in Fig. 2, phagocytic activity of PEM was significantly higher than that of HKM. This indicates that phagocytic activity of HKM was elevated after they were released from the head kidney, presumably in the peritoneal cavity. On the other hand, phagocytic activity of PEG was 1.7 times higher than that of HKG, but the difference was not significant.

\section{Activation of the Migrated HKM by PEC}

In order to clarify whether the migrated HKM were activated by $R P C$ or by leukocytes which had migrated to the peritoneal cavity, HKM obtained from a normal fish were membrane-separately incubated with $\kappa$-carrageenantreated RPC or PEC which was separated $3 \mathrm{~h}$ after $\kappa$-carrageenan injection $(2 \mathrm{mg} / 100 \mathrm{~g}$ body weight). The RPC consisted of lymphocytes $(89.7 \pm 2.6 \%)$, macrophages $(8.9 \pm 2.3 \%)$ and granulocytes $(1.4 \pm 0.9 \%)$, and the PEC consisted of lymphocytes $(74.5 \pm 3.6 \%)$, macrophages $(7.5 \pm 1.1 \%)$ and granulocytes $(18.0 \pm 4.7 \%)$ when examined by visual observation of the smear preparation.

One milliliter of HKM suspension $\left(2.5 \times 10^{6}\right.$ cells $/ \mathrm{m} l$ of RPMI-1640-PA) was placed into a $15 \mathrm{~m} /$ conical tube (Falcon 2096, Becton Dickinson Labware) and a culture insert (Nunc 136781, Nunc Products, Roskilde, Denmark) was placed on it. To this insert was added $0.5 \mathrm{~m} l$ of $\kappa$-carrageenan-treated RPC suspension $\left(1 \times 10^{6}\right.$ cells $/ \mathrm{m} l$ of RPMI1640-PA) or PEC suspension $\left(1 \times 10^{6}\right.$ cells $/ \mathrm{ml}$ of RPMI1640-PA) and then the insert was incubated at $22^{\circ} \mathrm{C}$ for 12 b. After removing the insert, the HKM were washed three times with RPMI-1640-P and assayed for their phagocytic activity.

As seen in Fig. 3, the phagocytic activity of HKM greatly increased when incubated with PEC, but did not change when incubated with $\kappa$-carrageenan-treated RPC, suggesting that the migrated HKM was activated not by RPC, but

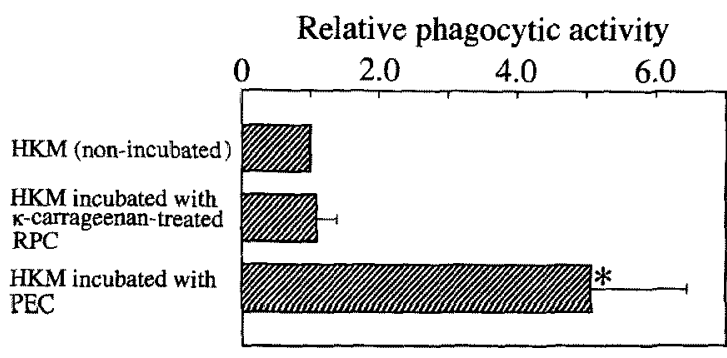

Fig. 3. Phagocytic activity of head kidney macrophages (HKM) after being membrane-separately incubated with $\kappa$-carrageenan-treated resident peritoneal cells (RPC) or peritoneal exudate cells (PEC) which was separated $3 \mathrm{~h}$ after $\kappa$-carrageenan injection $(2 \mathrm{mg} / 100 \mathrm{~g}$ body weight).

Columns and bars represent the means \pm S.E. of the quadruplicated experiments. *Significantly different from non-incubated HKM.

by leukocytes which had migrated to the peritoneal cavity.

\section{Discussion}

It has been reported that injection of $\beta$-1,3-glucan (lentinan, schizophyllan, scleroglucan) or $\kappa$-carrageenan significantly increased the survival rate of carp after being challenged with $E$. tarda or $A$. hydrophila. ${ }^{1,2,6)}$ The present work revealed that the mechanism underlying the high survival rate was different between fish treated with $\beta$-1,3-glucans and those treated with $\kappa$-carrageenan. $\beta$-1,3-glucans strongly activated carp ACP and HKP, while $\kappa$-carrageenan had little influence either on ACP or on the phagocytic and respiratory burst activities of HKP, yet it greatly enhanced the migration of phagocytes to the peritoneal cavity and concurrently elevated their phagocytic activity. In $\kappa$-carrageenan-injected $f i s h$, the early elimination of challenge bacteria by such mobilized and activated phagocytes would probably be responsible for their high survival rate.

The $\kappa$-carrageenan-elicited peritoneal exudate phagocytes would have mostly migrated from the head kidney, since it was confirmed in a preliminary experiment that injection of $\kappa$-carrageenan has little influence on the number of spleen phagocytes. The disparity between the number of phagocytes released from the head kidney and that which appeared in the blood and peritoneal cavity could probably be attributable to the newly produced phagocytes in the head kidney.

The activation of HKP by $\beta-1,3$-glucans appears to be closely related to the complement-activating potency of glucans since C3-receptors on carp HKP greatly increased after glucan injections (unpublished data). On the other hand, the activation of the phagocytic activity of the migrated HKP (predominantly macrophages and neutrophils) would probably be mediated by cytokine(s), be cause the phagocytic activity of the head kidney macrophages was elevated by incubation with leukocytes which had migrated to the peritoneal cavity. Mammalian macrophages are activated by various cytokines including interferon- $\gamma($ IFN- $\gamma$ ), interleukin-1 $\beta$ (IL-1 $\beta)$, IL-2, macrophage migration inhibitory factor (MIF) and tumor necrosis factor- $\alpha($ TNF- $\alpha) .{ }^{18)}$ More recently cDNA of rainbow trout IL-1 $\beta$ was cloned, ${ }^{19)}$ but no molecular information has 
been reported on other cytokines in fish. Our results suggest that peritoneal exudate cells which are activated already in vivo may be a useful source of genes for fish cytokines as well as or rather than cells stimulated in vitro.

\section{References}

1) T. Yano, R. E. P. Mangindaan, and H. Matsuyama: Enhancement of the resistance of carp Cyprinus carpio to experimental Edwardsiella tarda infection, by some $\beta$-1,3-glucans. Nippon Suisan Gakkaishi, 55, 1815-1819 (1989).

2) T. Yano, H. Matsuyama, and R. E. P. Mangindaan: Polysaccharide- induced protection of carp, Cyprinus carpio L., against bacterial infection. J. Fish Dis., 14, 577-582 (1991).

3) R. E. P. Mangindaan: Protective effect of $\beta-1,3$-glucans against bacterial infections in carp and yellowtail. Ph.D. thesis, Kyushu University, Japan, 1992.

4) B. Robertsen, G. Rørstad, R. Engstad, and J. Raa: Enhancement of non-specific disease resistance in Atlantic salmon, Salmo salar L., by a glucan from Saccharomyces cerevisiae cell walls. J. Fish Dis., 13, 391-400 (1990).

5) H. Noda, H. Amano, K. Arashima, S. Hashimoto, and K. Nisizawa: Antitumour activity of polysaccharides and lipids from marine algae. Nippon Suisan Gakkaishi, 55, 1265-1271 (1989).

6) K. Fujiki, D. H. Shin, M. Nakao, and T. Yano: Protective effect of $\kappa$-carrageenan against bacterial infections in carp Cyprinus carpio. J. Fac. Agr., Kyushu Univ., 42, (in press).

7) J. S. Craigie: Cell walls, in "Biology of the Red Algae" (ed. by K. M. Cole and R. G. Sheath), Cambridge University Press, New York, 1990, pp. 227-233.

8) H. Matsuyama, R. E. P. Mangindaan, and T. Yano: Protective effect of schizophyllan and scleroglucan against Streptococcus sp. infection in yellowtail (Seriola quinqueradiata). Aquaculture, 101, 197-203 (1992).

9) J. B. Jørgensen, G. J. E. Sharp, C. J. Secombes, and B. Robertsen:
Effect of a yeast-cell-wall glucan on the bactericidal activity of rainbow trout macrophages. Fish Shellfish Immunol., 3, 267-277 (1993).

10) J. B. Jørgensen, and B. Robertsen: Yeast $\beta$-glucan stimulates respiratory burst activity of Atlantic salmon (Salmo salar $L$.) macrophages. Dev. Comp. Immunol, 19, 43-57 (1995).

11) D. Chen and A. J. Ainsworth: Glucan administration potentiates immune defence mechanisms of channel catfish, Ictalurus punctatus Rafinesque. J. Fish Dis., 15, 295-304 (1992).

12) G. Chihara, J. Hamuro, Y. Maeda, Y. Arai, and F. Fukuoka: Fractionation and purification of the polysaccharides with marked antitumor activity, especially Lentinan, from Lentinus edodes (Berk.) Sing. (an edible mushroom). Cancer Res., 30, 2776-2781 (1970).

13) T. Yano, Y. Hatayama, H. Matsuyama, and M. Nakao: Titration of the alternative complement pathway activity of representative cultured fishes. Nippon Suisan Gakkaishi, 54, 1049-1054 (1988).

14) A. F. Rowley: Collection, separation and identification of fish leukocytes, in "Techniques in Fish Immunology-I" (ed. by J. S. Stolen, T. C. Fletcher, D. P. Anderson, B. S. Roberson and W. B. van Muisvinkel), SOS Publications, New York, 1990, pp. 113-136.

15) H. Matsuyama, T. Yano, T. Yamakawa, and M. Nakao: Opsonic effect of the third complement component (C3) of carp (Cyprinus carpio) on phagocytosis by neutrophils. Fish Shellfish Immunol., 2, 69-78 (1992).

16) G. A. W. Rook, J. Steele, S. Umar, and H. M. Dockrell: A simple method for solubilisation of reduced NBT, and its use as a colorimetric assay for activation of human macrophages by $y$-interferon. J. Immunol. Methods, 82, 161-167 (1985).

17) Y. Itazawa, T. Takeda, K. Yamamoto, and T. Azuma: Determination of circulating blood volume in three teleosts, carp, yellowtai and porgy. Japan. J. Ichthyol., 30, 94-101 (1983).

18) A. Celada, and C. Nathan: Macrophage activation revisited. Immunology Today, 15, 100-102 (1994).

19) J. Zou, C. Cunningham, and C. J. Secombes: Rainbow trout recombinant interleukin $1 \beta$ : expression, renaturation and determination of the biological activities. Dev. Comp. Immunol., 21, 192 (1997). 